\title{
Numerical Analysis on Influence of Underground Space Construction on Adjacent Tunnel
}

\author{
Jianwu Gong ${ }^{1, a}$, Xin Wang ${ }^{1, b}$ and Hao Sheng ${ }^{1, c}$ \\ ${ }^{1}$ School of Urban Construction, Wuhan University of Science and Technology, Wuhan, Hubei \\ 430065, P.R. China \\ ajgjwang@126.com, b1486308836@qq.com, c 467222734@qq.com
}

\begin{abstract}
Keywords: adjacent tunnel; underground space; interaction; numerical analysis
Abstract. The construction of underground engineering will bring risks and potential hazards to the adjacent tunnel engineering. A series of numerical analysis models have been built to analyze the influence of underground engineering construction having on adjacent tunnel structure under different horizontal distance. According the simulation results, when the distance from underground space to tunnel is less than $10 \mathrm{~m}$, the interaction is fairly remarkable. It is suggested to take strong pre-consolidation measure during the construction of tunnel. The critical distance of underground space to adjacent tunnel is about $20 \mathrm{~m}$. When the distance is less than $20 \mathrm{~m}$, the adverse effect must be taken into consideration during the design and construction of adjacent tunnels.
\end{abstract}

\section{Introduction}

The construction of highway tunnels is rapid increasing with the development of transportation infrastructure in China. It is usually inevitable for tunnel to cross complex ground conditions, and the development and utilization of underground space will bring lots of risks and potential hazards to the adjacent tunnel engineering. How to balance the relationship between underground engineering and adjacent tunnel becomes an important problem to be solved in rock and soil engineering [1,2].

In recent years, many researchers have carried out a wide range of research according to practice engineering of foundation pit and underground space [3-5]. In the field of highway tunnel construction in mining area, the researchers mainly aim at goaf area under tunnel. There is less research of tunnel crossing adjacent mining area [6,7].

Base on numerical simulation, the influence regulation of underground engineering construction on adjacent tunnel structure is evaluated with different horizontal distance.

\section{Analysis Condition and Parameters}

Analysis Condition.The distance from model boundary to tunnel is more than 5 times the tunnel excavation span in numerical simulation model. The model was horizontal fixed at left and right boundary, vertical fixed at bottom boundary. The underground space is set as $3 \times 9 \mathrm{~m}(\mathrm{H} \times \mathrm{B})$.

Five kinds of working conditions were selected with different distances between underground space and adjacent tunnel: 5m, $10 \mathrm{~m}, 20 \mathrm{~m}, 30 \mathrm{~m}$ and $40 \mathrm{~m}$.

Mechanical Parameters. Considering adverse conditions, the V-grade surrounding rock is selected in the simulation model. And the mechanical parameters of surrounding rock is shown in Table 1 , which is determined by code for design of road tunnel and relative engineering[8,9].

Table 1. Mechanical parameters of surrounding rock

\begin{tabular}{cccccc}
\hline Item & $\begin{array}{c}E \\
{[\mathrm{GPa}]}\end{array}$ & $\mu$ & $\begin{array}{c}\gamma \\
{\left[\mathrm{kN} / \mathrm{m}^{3}\right]}\end{array}$ & $\begin{array}{c}c \\
{[\mathrm{kPa}]}\end{array}$ & $\begin{array}{c}\varphi \\
{\left[{ }^{\circ}\right]}\end{array}$ \\
\hline $\begin{array}{c}\text { V-grade } \\
\text { rock }\end{array}$ & 1.2 & 0.38 & 20 & 80 & 27 \\
\hline
\end{tabular}




\section{Results and Analysis}

Periphery Displacement Analysis. Table 2 shows the periphery displacement value of tunnel caused by adjacent underground engineering construction at different distance. Figure 1 is the relation curve of displacement value with corresponding distance. (The positive value represents upward displacement for crown and bottom settlement, and relative reduction for convergence.)

Table 2. Deformation value of surrounding rock in different distance of underground space to adjacent tunnel

\begin{tabular}{ccccccc}
\hline $\begin{array}{c}\text { Distance of } \\
\text { underground } \\
\text { space to adjacent } \\
\text { tunnel } \\
{[\mathrm{m}]}\end{array}$ & $\begin{array}{c}\text { Crown } \\
\text { settlement }\end{array}$ & $\begin{array}{c}\text { Bottom } \\
\text { deformation }\end{array}$ & $\begin{array}{c}\text { Left side wall } \\
\text { deformation }\end{array}$ & $\begin{array}{c}\text { Right side } \\
\text { wall } \\
\text { deformation }\end{array}$ & $\begin{array}{c}\text { Vertical } \\
\text { convergence }\end{array}$ & $\begin{array}{c}\text { Horizontal } \\
\text { convergence }\end{array}$ \\
\hline 5 & -9.6 & 5.7 & -10.2 & 2.4 & 15.3 & -12.6 \\
10 & -5.3 & 1.1 & -2.9 & 1.1 & 6.4 & -4.0 \\
20 & -3.3 & -1.5 & -0.1 & 0.6 & 1.8 & -0.7 \\
30 & -2.5 & -1.8 & 0.2 & 0.5 & 0.7 & -0.3 \\
40 & -2.1 & -1.7 & 0.2 & 0.1 & 0.4 & 0.1 \\
\hline
\end{tabular}

From Table 2, it can be seen that tunnel structure was stretched in the transverse direction due to the influence of adjacent underground space. In a certain distance, the periphery displacement of tunnel increased gradually with the decrease of distance between underground space and adjacent tunnel. The deformation at the left side wall of tunnel is the most obvious.

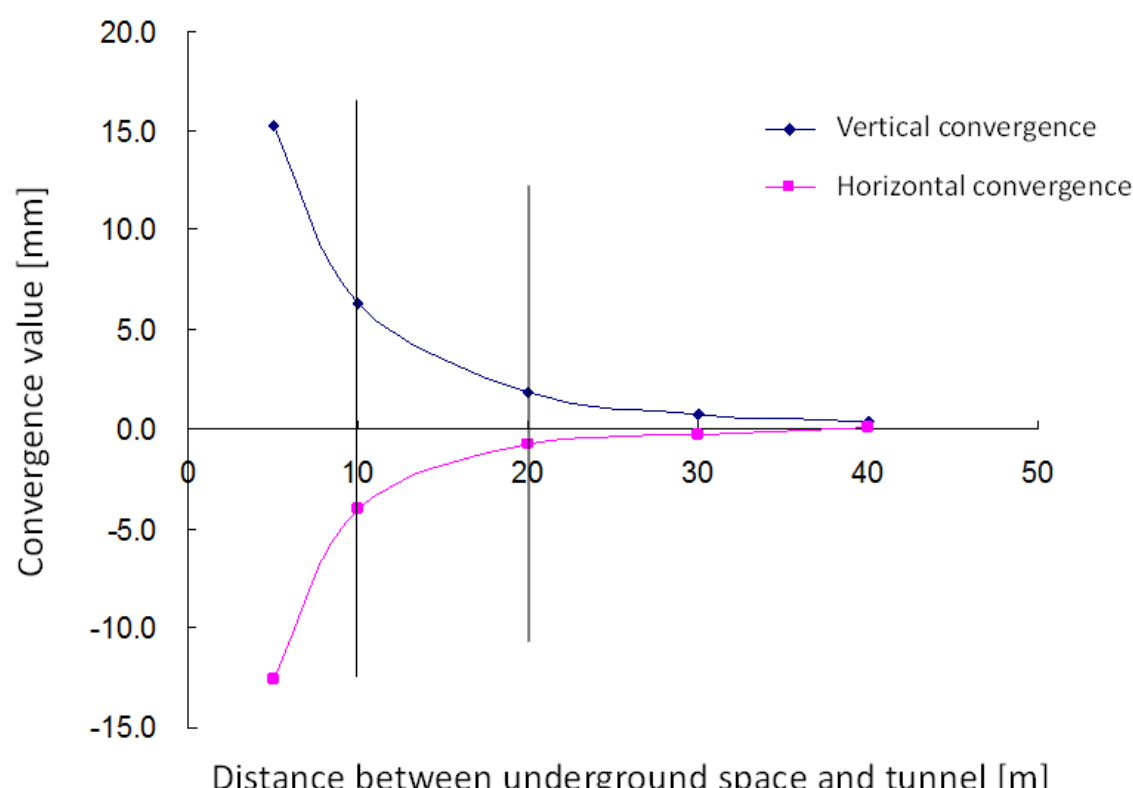

Figure 1. Curves of deformation value of surrounding rock with distance of underground space to adjacent tunnel

According to Figure 1, when the distance between underground space and adjacent tunnel is less than $10 \mathrm{~m}$, the influence of distance change on periphery displacement of tunnel is dramatic. And the characteristic displacement decreases gradually with the distance from $10 \mathrm{~m}$ to $20 \mathrm{~m}$. When the distance is more than $20 \mathrm{~m}$, the periphery displacement of tunnel nearly keeps stable. The result shows that the main influence scope of underground space to adjacent tunnel is about $20 \mathrm{~m}$. 
Internal Force Analysis of Tunnel. Table 3 shows the axial force of primary lining and moment of secondary lining at the left side wall of tunnel caused by adjacent underground space at different distance.

Table 3. Internal force of Lining in different distance of underground space to adjacent tunnel

\begin{tabular}{ccc}
\hline $\begin{array}{c}\text { Distance of underground } \\
\text { space to adjacent tunnel } \\
{[\mathrm{m}]}\end{array}$ & $\begin{array}{c}\text { Axial force of } \\
\text { primary lining } \\
{[\mathrm{kN}]}\end{array}$ & $\begin{array}{c}\text { Moment of } \\
\text { secondary lining } \\
{[\mathrm{kN} \cdot \mathrm{m}]}\end{array}$ \\
\hline 40 & 4166 & 915 \\
30 & 4211 & 948 \\
20 & 4369 & 996 \\
10 & 5230 & 1216 \\
5 & 6968 & 1428 \\
\hline
\end{tabular}

According to Table 3, when the distance from underground space to adjacent tunnel is $40 \mathrm{~m}$, the internal force of tunnel supporting structure is almost the same to that without adjacent underground space. When the distance reduces to $30 \mathrm{~m}$, the internal force decreases a little. While the distance reduces to $20 \mathrm{~m}$, the changing trend of internal force decreases rapidly. The closer the distance is, the greater the change is. And when the distance from underground space to adjacent tunnel is less than $10 \mathrm{~m}$, the influence of distance change having on the internal force of tunnel supporting structure is dramatic.

Rock Plastic Zone Analysis. With the different distance, the scope of surrounding rock mass plastic zone of tunnel structure and adjacent underground space can be got in different working conditions.

Based on the analysis results, it can be deduced that the distance of underground space and tunnel have obvious influence on the distribution of plastic zone in surrounding rock mass. When the distance is small, the plastic zone is connected between the tunnel and the underground space, and the scope of plastic zone is relatively larger, which is very dangerous for the stability of tunnel structure. When the distance increases to $10 \mathrm{~m}$, the plastic zone reduces, but the scope is still connected between the tunnel and the underground space. When the distance increases to $20 \mathrm{~m}$, the plastic zone reduces obviously, and the interaction of tunnel and adjacent underground space becomes weaker gradually. While the distance is $40 \mathrm{~m}$, the scope of plastic zone in rock mass almost keeps unchanged. Therefore, the critical distance from underground space to adjacent tunnel is $20 \mathrm{~m}$ in terms of rock plastic zone distribution

According to the analysis of periphery displacement of tunnel, internal force of supporting structure and distribution of surrounding rock plastic zone, it can be deduced that the main influence scope of underground space on adjacent tunnel structure is about $20 \mathrm{~m}$.

\section{Conclusions}

Under different horizontal distance from underground space to adjacent tunnel, a series of numerical analysis models have been built. Through analyzing the influence of underground engineering construction having on adjacent tunnel structure, some conclusions were presented as followings.

The underground space has remarkable influence on the stability of tunnel structure and surrounding rock. When the distance from underground space to adjacent tunnel is less than $10 \mathrm{~m}$, the adverse influence is fairly obvious. It is suggested to take strong pre-consolidation measure during the construction of tunnel. In a certain distance, the influence decreases gradually with the increase of distance from underground space to adjacent tunnel. When the distance is less than $20 \mathrm{~m}$, the adverse effect must be taken into consideration during the construction of adjacent tunnels. 


\section{Acknowledgements}

This work was financially supported by the Research Project of Education Department of Hubei Province of China (Q20111101) and National Natural Science Foundation of China (51208395).

\section{References}

[1] Hong Chen, Zhenhuan Chu and Qingguo Zeng: Soil Engineer and Foundation, Vol.27 (2014), p.73 (in Chinese)

[2] Caichu Xia, Jianwu Gong and Ying Tang: Chinese Journal of Rock Mechanics and Engineering, Vol.26(2007),p. 44 (in Chinese)

[3] Wei Wang: Building Construction, Vol.34(2012),p.1181. (in Chinese)

[4] Haiyang Tian: Chinese Journal of Underground Space and Engineeting, Vol.10(2014),p.663. (in Chinese)

[5] Fengjun Zhu: Shanxi Architecture, Vol.41(2015),p.76. (in Chinese)

[6] Jin Zhu, Chaoyue Zhou: Journal of Highway and Transportation Research and Development, No.7(2015),p.228. (in Chinese)

[7] Yong Fang, Chaoyue Zhou and Shubin Liu: Journal of Hunan University(Natural Sciences), Vol.42(2015),p.100. (in Chinese)

[8] Nantao Song, Weitao Chen and Mingnian Wang: Railway Construction Technology, No.3 (2007),p.48. (in Chinese).

[9] The Professional Standards Compilation Group of People’s Republic of China. Code for design of road tunnel. (China Communications Press, China 2004.) (in Chinese) 